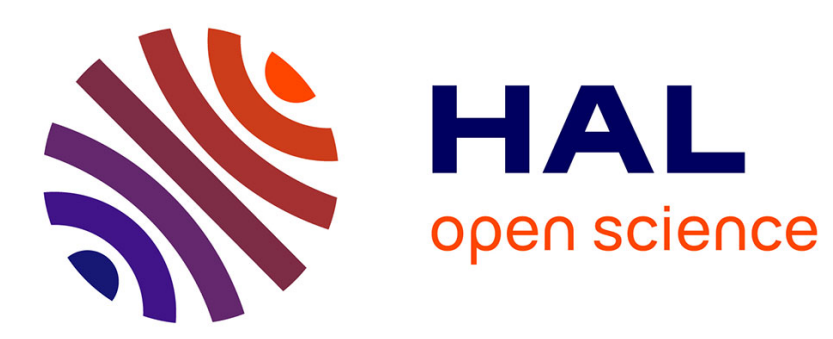

\title{
The Price Stability Oriented Monetary Policy of the ECB: An Assessment
}

\author{
Claudio Morana
}

\section{To cite this version:}

Claudio Morana. The Price Stability Oriented Monetary Policy of the ECB: An Assessment. Applied Economics, 2006, 38 (17), pp.2007-2020. 10.1080/00036840500427312 . hal-00581894

\section{HAL Id: hal-00581894 https://hal.science/hal-00581894}

Submitted on 1 Apr 2011

HAL is a multi-disciplinary open access archive for the deposit and dissemination of scientific research documents, whether they are published or not. The documents may come from teaching and research institutions in France or abroad, or from public or private research centers.
L'archive ouverte pluridisciplinaire HAL, est destinée au dépôt et à la diffusion de documents scientifiques de niveau recherche, publiés ou non, émanant des établissements d'enseignement et de recherche français ou étrangers, des laboratoires publics ou privés. 


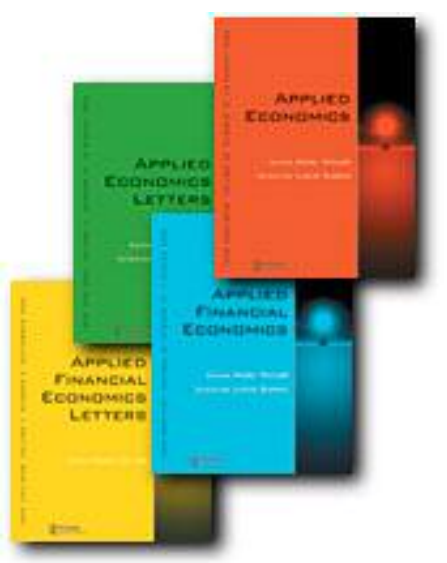

The Price Stability Oriented Monetary Policy of the ECB: An Assessment

\begin{tabular}{|r|l|}
\hline Journal: & Applied Economics \\
\hline Manuscript ID: & APE-04-0212.R2 \\
\hline Journal Selection: & Applied Economics \\
\hline Date Submitted by the \\
Author: & 05-May-2005 \\
\hline JEL Code: & $\begin{array}{l}\text { C32 - Time-Series Models < C3 - Econometric Methods: } \\
\text { Multiple/Simultaneous Equation Models < C - Mathematical and } \\
\text { Fluctuations, Methods, E30 - General < E3 - Prices, Business } \\
\text { Economics, E40 - General }<\text { E4 - Macroeconomics and Monetary and Interest Rates < E - } \\
\text { Macroeconomics and Monetary Economics }\end{array}$ \\
\hline Keywords: & monetary policy, price stability, businness cycle, Euro Area \\
\hline
\end{tabular}

\section{Manuscript Central ${ }^{\text {H }}$}




\title{
The Price Stability Oriented Monetary Policy of the ECB: An Assessment
}

\author{
May 2005
}

\begin{abstract}
The definition of price stability adopted by the ECB has recently been criticised in the literature, particularly for being unable to fully anchor inflation expectations and creating a deflation risk. In the paper we provide empirical evidence against these claims. Despite the unfavourable macroeconomic conditions for the euro area since 2001, monetary policy management has lead to the setting of the policy rate at levels compatible with trend inflation (the long-run inflation forecast) in the range 1\%-3\%, and therefore without affecting negatively the inflation outlook.
\end{abstract}

J.E.L. classification: C32, E3, E4.

Keywords: monetary policy, price stability, business cycle. 


\section{Introduction}

The definition of price stability adopted by the European Central Bank (ECB) in October 1998, i.e. an harmonised CPI inflation rate of below $2 \%$ in the mediumterm, has recently been criticised in the literature. Firstly, it has been argued that, in order to maintain the focus of monetary policy on persistent inflation dynamics, a more prominent role should be given to core inflation measures or even the price stability objective should be stated in terms of a core inflation rate. $^{1}$ In fact, monetary policy should not attempt to stabilise transient fluctuations in inflation, but only set the policy rate at levels compatible with the achievement of the medium term price stability objective. Secondly, while the quantitative definition of price stability has in general been praised in the literature for yielding transparency and accountability to the monetary policy making process, the level of the ceiling $(2 \%)$ has been criticised for being too low. ${ }^{2}$ There are four main reasons why the inflation ceiling should not be too low, namely the likely upward bias in the HICP inflation rate, nominal downward rigidities which may prevent the adjustment of real variables to the equilibrium values, persistent inflation differentials across euro area members which may lead to frequent deflationary episodes for some of the countries, and the fact that, once attained the zero bound for the nominal interest rate, monetary policy may loose much of its effectiveness in stimulating aggregate demand and fighting deflation. Hence, it is feared that the low inflation objective may create a deflation risk, particularly in the presence of a rapid contraction in real activity. Thirdly, the price stability definition appears to be ambiguous and asymmetric, being the lower bound, contrary to the upper bound, not clearly stated, and unable to fully anchor inflation expectations. ${ }^{3}$ Hence, either a lower bound for inflation should be stated or price stability should be defined in terms of a point inflation rate.

Following the evaluation of its monetary policy strategy in May 2003, the ECB has confirmed both the price stability definition and the two-pillar strategy. However, also in the view of the above mentioned criticism, clarifications have been made ${ }^{4}$. Firstly, it has been pointed out that the inflation objective should be intended not only as an harmonised CPI inflation rate of below $2 \%$ in the medium term, but also close to $2 \%$. Hence, the price stability definition should

\footnotetext{
${ }^{1}$ See Gros et al. (2001) and Alesina et al. (2001).

${ }^{2}$ See Fitoussi and Creel (2002), Svensson (2003), Fitoussi (2003), Wyplosz (2003), and von Hagen and Hofman (2004).

${ }^{3}$ See Svensson (2002a,b, 2003) and IMF (2002).

${ }^{4}$ See ECB (2003).
} 
not increase the deflation risk, aiming however at an inflation rate level which is not so high to impose costs to society. Moreover, as the assessment shows, the price stability definition has actually been effective in anchoring inflation expectations, which have previously been shown to be determined by both forward looking and backward looking components (Sauch, 2004). Finally, the medium term focus implies that the ECB is not engaging in fine tuning economic activity, and that the policy rate is set according to the evolution of trend inflation dynamics.

In this paper we have further assessed the validity of the price stability definition adopted by the ECB by means of a small scale macroeconometric model for the euro-12 area. The empirical approach allows to determine the shocks determining economic fluctuations in the euro area and assess ECB monetary policy response over the period 1999-2003. Our assessment of the macroeconomic conditions points to adverse supply shocks and aggregate demand shortages leading to a fall of output below potential since 2001, also as a consequence of the burst of the stock market bubble and declining real stock market prices. A financial shock, possibly reflecting investor's uncertainty, would be responsible for the current stock market undervaluation, the latter contributing to depress real output. We interpret current developments in excess real money balances as reflecting the effects of the portfolio shift towards monetary assets following the stock market crash in 2000, and the increase in stock market and macroeconomic uncertainty afterwards. The slow down in economic activity and the expectations of persistence of this phenomenon in the medium term may have also contributed to keep the preference of investors biased towards liquidity. Moreover, while the inflation cycle points to excess inflation relatively to trend due to transitory shocks, trend inflation, as measured by the annualised permanent component in the GDP deflator inflation rate, is currently close to $1.5 \%$, suggesting that the monetary accommodation may have been appropriate also to preempt deflationary threats. Finally, a simulation exercise, conditional to the non favourable macroeconomic context, suggests that the current definition of price stability has implied the setting of the policy interest rate at levels compatible with trend inflation (the long-run inflation forecast) in the range 1\%-3\%, and therefore without affecting negatively the inflation outlook. Hence, we do not find empirical support for the recent criticisms to the price stability definition. Actually, as also argued in Bordo and Filardo (2004), the two-pillar strategy could be very effective to manage monetary policy in deflationary environments, given the prominent role, among the various instruments, nominal monetary base growth will have in such 
circumstances. ${ }^{5}$

After this introduction, the paper is organised as follows. In section two we sketch the theoretical framework describing the macroeconomy in the long-run. In section three we present the empirical results. Finally, in section four we conclude.

\section{Theoretical framework}

The economy is described by six endogenous variables: log real GDP $\left(y_{t}\right)$, GDP deflator inflation $\left(\pi_{t}\right)$, log real M3 balances $\left(r m_{t}\right)$, the short term nominal interest rate $\left(i_{t}\right)$, the long term nominal interest rate $\left(l_{t}\right)$, and a log real stock market price index $\left(f_{t}\right){ }^{6}$ Below we provide the basic structure of the steady-state of the model. Coherent with the cointegration framework employed in the paper, the key structural relations are expressed in terms of cointegration relationships. On the other hand, we allow the short-run behaviour of the economy to be described by means of a vector equilibrium correction model (VECM).

Coherent with the classical framework, we assume separation between the real side and the nominal side of the economy in the long-run. Hence, we assume two different forces driving the long-run evolution of the variables, i.e. an i.i.d. real shock associated with productivity $\left(v_{\theta, t}\right)$, and an i.i.d. nominal shock $\left(v_{\beta, t}\right)$ associated with ECB monetary policy decisions and, in particular, with the dynamics of the excess nominal money growth process. Both shocks are permanent and determine the trend evolution of the real and nominal variables in the system through the $\mathrm{I}(1)$ common trends

$$
\begin{gathered}
\theta_{t}=k_{\theta}+\theta_{t-1}+v_{\theta, t} \quad k_{\theta}>0, \\
\beta_{t}=\beta_{t-1}+v_{\beta, t} .
\end{gathered}
$$

\footnotetext{
${ }^{5}$ See Morana (2004) for evidence in favour of the inflationary effects that monetary base growth may exercise also when the economy is in a deflation trap, with short term nominal interest rates at the zero lower bound.

${ }^{6}$ In this study quarterly euro-12 area data from 1980:Q1 through 2003:Q4 have been used. As a measure of M3, seasonally adjusted quarterly averages of the month-end stocks of M3 are used. Nominal GDP is in millions of euro and has been seasonally adjusted and converted to euro via the irrevocable fixed conversion rates of 31 December 1998. The real and nominal GDP series are used to construct the GDP deflator. The short term nominal intertest rate has been computed using 3-month money market interest rates for the euro area countries, while the long term nominal interest rate has been computed from 10-year government bond yields or close substitutes. The stock market index is taken from Datastream (TOTMKEM) and converted into euro using a synthetic US\$/EUR exchange rate series.
} 
We assume that in the steady-state output is fully determined by the technology variable $\theta_{t}$, while inflation is determined from the excess nominal money growth process $\beta_{t}$. Hence, $y_{t}^{*}=\gamma_{1} \theta_{t}$ and $\pi_{t}^{*}=\gamma_{2} \beta_{t}$.

Given two common trends in a system of six I(1) cointegrated variables, four cointegration relationships can be expected to describe the long-run linkages relating the variables included in the information set. The candidate relationships are

1) a Cambridge money demand equation

$$
r m_{t}=\phi_{m} y_{t}+\varepsilon_{m, t} \quad \phi_{1}>0
$$

where $\varepsilon_{m, t} \sim I(0)$ and $\phi_{m}$ is the real money demand elasticity of real output; ${ }^{7}$

2) a present value relationship linking the real stock market index and output

$$
f_{t}=\phi_{f} y_{t}+\varepsilon_{f, t} \quad \phi_{f}>0
$$

where $\varepsilon_{f, t} \sim I(0) ;^{8}$

3) a term structure relationship linking the yields on short term bills and long term bonds

$$
l_{t}=i_{t}+\phi_{l}+\varepsilon_{l, t} \quad \phi_{l}>0
$$

where $\varepsilon_{l, t} \sim I(0)$ and $\phi_{l}$ is a term premium;

4) a Fisher parity condition

$$
i_{t}=\phi_{f p, t}+\phi_{\pi} \pi_{t}+\varepsilon_{i, t} \quad \phi_{\pi}>0,
$$

where $\varepsilon_{i, t} \sim I(0)$ and $\phi_{f p, t}$ is the sum of the constant real short term interest rate and the time-varying average inflation risk premium. ${ }^{9}$ Alternatively, this equation can be interpreted as a "Taylor-like" monetary policy rule.

\footnotetext{
${ }^{7}$ Note that this is not a restrictive assumption, since the actual specification of the longrun money demand equation is obtained by the error correction terms entering the real money balances dynamic equation in the VECM model, and may include, for instance, a proxy for wealth or the opportunity cost of holding money.

${ }^{8}$ This relationship can be derived from the Gordon growth model, assuming a proportional relationship between real dividends and output.

${ }^{9}$ The motivation for a time-varying parameter inflation risk premium can be found in the process of economic convergence, in the countries currently belonging to the Euro area, following the introduction of the Maastricht Treaty in 1992. See section 3.1 for additional details.
} 
The structure of the model show long-run separation (Konishi and Granger, 1992; Granger and Haldrup, 1997) of the real and nominal sides of the economy, since the cointegration relationships involve either real or nominal variables. This property can also be gauged from the steady-state representation of the model, which, neglecting constants, can be written as follows

$$
\left[\begin{array}{c}
y_{t}^{*} \\
f_{t}^{*} \\
r m_{t}^{*} \\
i_{t}^{*} \\
l_{t}^{*} \\
\pi_{t}^{*}
\end{array}\right]=\left[\begin{array}{cc}
\gamma_{1} & 0 \\
\phi_{f} \gamma_{1} & 0 \\
\phi_{m} \gamma_{1} & 0 \\
0 & \phi_{\pi} \gamma_{2} \\
0 & \phi_{l} \gamma_{2} \\
0 & \gamma_{2}
\end{array}\right]\left[\begin{array}{c}
\theta_{t} \\
\beta_{t}
\end{array}\right]
$$

The steady-state displays monetary neutrality, as the nominal trend $\left(\beta_{t}\right)$ does not have any impact on the real variables $\left(y_{t}, f_{t}, r m_{t}\right)$ in the long-run.

\section{Empirical results}

\subsection{Cointegration analysis}

According to standard ADF tests all the series analysed should be modelled as I(1) processes. ${ }^{10}$ Following standard tests for specification analysis, two lags have been included in the VAR model for estimation. According to results of Cassola and Morana (2002, 2004), the long-run structure sketched in the previous section characterised the euro-12 area economy over the period 1980:1-2000:4, except from the Fisher relationship, which has previously been modelled as a time-invariant cointegration relationship. However, according to Bagliano et al. (2004), the inclusion of an unrestricted step dummy variable would be necessary to model the break process in the ex-post real interest rate. A more appropriate specification of the Fisher relation for the euro area would embody in fact a single downward shift in the mean risk premium starting at least in January 1999. In fact, with the introduction of the single monetary policy and the explicit price stability objective, under the assumption of a credible monetary policy, it would be appropriate

\footnotetext{
${ }^{10}$ Although recent evidence would point to long memory and structural breaks as the cause of persistence of the euro area inflation rate (see for instance Morana, 2005), in the light of the econometric frameowork employed, modelling it as an I(1) process may be considered preferable to the modelling of the variable as an $\mathrm{I}(0)$ process, given the strong shock persistence shown by long memory processes.
} 
to assume a reduction in inflation uncertainty, and therefore in the inflation risk premium. Instability in the average risk-premium has been investigated by means of Markov-switching model. As shown in the Appendix we have found evidence of a break point in the ex-post short term real interest rate in 1996:1. Several explanations can be proposed for this finding. Firstly, in order to meet the Maastricht Treaty's convergence criteria, virtuous policies had to be implemented in the traditionally high inflation countries. This lead to low inflation rates for all the candidate countries for most of the 1990s, which may have determined a reduction in inflation uncertainty, due to the negative relationship between the level of the inflation rate and its volatility; moreover the convergence of inflation rates towards the lower levels of the more virtuous countries may have also lead to a progressive reduction in interest rate spreads and levels. Secondly, two events are likely to have had a strong impact on the acceleration of the convergence process, i.e. the confirmation in December 1995 by the European Council of the starting date for the common monetary policy (January 1999), and the determination in May 1998 of the list of the countries eligible for admission to the Monetary Union.

According to the Johansen (1988) trace test statistic, ${ }^{11}$ the evidence points to two valid cointegrating vectors at the $1 \%$ significance level, three vectors at the $5 \%$ level and four vectors at the $10 \%$ level. A partially different result is provided by the error correction test, for which, differently from the trace test statistics, critical values for the exact sample size employed in the paper can be computed by response surfaces (see Ericsson and MacKinnon, 2002). The test suggests that all the estimated long-run relationships are valid cointegrating vectors at the $5 \%$ level, apart from the real money demand relationships which is valid at the $9 \%$ level. ${ }^{12}$

In Table 1, Panel B, we have reported the estimated factor loading matrix. As is shown in the Table, real output reacts positively and significantly to the

\footnotetext{
${ }^{11}$ Critical values for the trace test statistic for the model with the step dummy have been computed using DISCO and are reported in Table 1.

${ }^{12}$ Bruggeman et al. (2003) consider a slightly different system from the one analysed in the

paper, also including the own return for M3. The time period investigated is also different (1980:2-2001:4) and they do not allow for a break in the Fisher parity equation. On the basis of Bartlett corrected statistics, they conclude in favour of two cointegrating vectors. Despite these results, also on the basis of the error correctig behaviour of the whole system, we think that the assumption of four cointegrating vectors is appropriate for our data. Results for the Ericsson and MacKinnon (2002) test are available upon request to the author. See also Brandt and Cassola (2004) and Bagliano et al. (2002).
} 
stock market disequilibrium and to the term structure imbalance (yield curve slope). The former result points to the presence of wealth effects/Tobin's "q" effects in the euro area, while the latter to the leading behaviour of the slope of the yield curve for economic performance. Moreover, real money balances correct relatively to excess real balances, closing the disequilibrium with real output, and relatively to the Fisher parity relation, falling as the imbalance between the nominal interest rate and the inflation rate increases, i.e. as the real interest rate increases. Interestingly, the real stock market index is close to be weakly exogenous for the long-run parameters, albeit its positive reaction to excess real money balances is significant at the $7 \%$ level. Also the error correcting behaviour of the nominal variables has a clear-cut economic interpretation. In fact, the nominal short term interest rate corrects with negative sign relatively to excess real money balances and relatively to the Fisher parity imbalance, suggesting that the nominal short term interest rate falls as real money balances increase and as inflation decreases; the long term nominal interest rate corrects with negative sign relatively to the slope of the yield curve and the Fisher parity imbalance, i.e. falling as the short term nominal interest rate falls or when it is expected to fall; finally, the inflation rate corrects with positive sign relatively to the Fisher parity disequilibrium.

\subsection{Common trends analysis}

The existence of four cointegration relationships among the six variables in the system implies that two common trends drive the long-run evolution of the economy. Given the evidence of long-run separation between the real and nominal sides of the economy, it can be expected that the two permanent shocks building up the two common trends be a real disturbance and a nominal disturbance, respectively. Coherent with the theoretical framework, we assume that the needed identifying restriction for the long-run impact matrix ${ }^{13}$ is a long-run neutrality restriction, implying that the nominal shock does not have a long-run impact on the real variables. We interpret the two permanent disturbances as a productivity shock $\left(\psi_{\theta}\right)$ and a monetary policy shock $\left(\psi_{\beta}\right)$, possibly related to the excess nominal money growth process. Also the additional restrictions needed to identify the

\footnotetext{
${ }^{13}$ Once the restrictions implied by cointegration and the orthogonality of the permanent shocks have been taken into account, $k \times(k-1) / 2$ additional restrictions need to be imposed on the long-run impact matrix, on the basis of economic theory, for exact identification. See the methodological Appendix.
} 
transitory shocks have been imposed in such a way that the economic interpretation of the structural errors is meaningful from an economic point of view. ${ }^{14}$ In particular, we have assumed that (i) the shock to the term structure $\left(v_{T S}\right)$ does not have a contemporaneous impact on output, inflation and real balances; (ii) the liquidity preference shock $\left(v_{S M}\right)$ does not have a contemporaneous impact on output and inflation; (iii) there is an underlying temporary shock to output $\left(v_{A D}\right)$ (interpretable as a demand shock) that does not have a contemporaneous impact on inflation; (iv) the shock to the Fisher relation $\left(v_{F H}\right)$ has a contemporaneous impact on all variables. The interpretation of the shocks is supported by the empirical results reported below.

\subsubsection{Forecast error variance decomposition}

The estimated long-run impact matrix, which can be seen as the empirical equivalent of equation (2.7), and the forecast error variance decomposition are reported in Table 2 and in Table 3, respectively. Note that, coherent with the theoretical structure, the real permanent shock has a not statistically significant long-run impact on the nominal variables, explaining only $8 \%$ of the residual long-run variability (see Table 2, Panel A and Table 3, Panel C). Therefore, the evidence points to long-run separation, conditional to the exactly identifying neutrality restriction, with two permanent shocks driving the long-run evolution of the real and nominal sides of the economy, respectively. Given their long-run impact, we interpret the real shock as a productivity shock and the nominal shock as an excess nominal money growth shock. Empirically, the separation between the real and nominal sides of the economy is evident already at the 5-year horizon, since, at that horizon, the productivity shock is the main cause of fluctuations in the real variables $(64 \%, 83 \%$ and $46 \%$, for output, real money balances and real stock prices, respectively), while the excess nominal money growth shock accounts for the bulk of variability in the nominal variables $(64 \%, 71 \%$ and $75 \%$, for short and long term nominal interest rates and inflation, respectively). On the other hand, transitory shocks explain the bulk of fluctuations in the short and medium term, and are the source of non-separation in the short term. In fact, up to three years aggregate demand shocks are the main source of output variability (96\% at 1 year; $40 \%$ at 3 years), while the Fisher relation shock is the main source of inflation

\footnotetext{
${ }^{14}$ In addition to the restrictions implied by the orthogonality of the transitory shocks and the orthogonality between the permanent and transitory shocks, $r(r-1) / 2$ additional restrictions, based on economic theory, need to be imposed on the contemporaneous impact matrix for exact identification. See the methodological Appendix.
} 
variability (46\% at 1 quarter), albeit also the productivity and excess nominal money growth shocks play some role (21\% and 33\%, respectively). Also, financial shocks (liquidity preference shocks) are the most important determinants of real stock market prices fluctuations in the short and medium term $(75 \%$ at 1 quarter; $44 \%$ at 3 years). Moreover, the short and long term nominal interest rates seem to share the same underlying factors of variability, namely, in the very short term (within one quarter), productivity $(28 \%$ and $22 \%$ ), excess nominal money growth (19\% and $23 \%$ ), term structure (28\% and $11 \%)$ and Fisher parity (17\% and $32 \%)$ shocks. Differently from the other variables, productivity shocks are the main cause of real money balances variability already in the short term (65\% within one year), albeit liquidity preference shocks also exercise a non negligible role in the short and medium term (27\% within one year, $18 \%$ within three years) and the Fisher parity shock in the very short term (19\% within one quarter). ${ }^{15}$

By comparing with the previous results of Cassola and Morana (2004, 2002), it is possible to note the increased importance assumed by the transitory liquidity preference shocks in accounting for real stock market prices variability in the short and medium term and the diminished importance of the productivity shock in accounting for interest rate variability in the short term. Other interesting differences concern the determination of inflation variability in the short term, which is now more related to both permanent shocks, and of real money balances variability, which is now accounted more heavily by productivity shocks. In the historical decomposition section below we provide an explanation for the observed dynamics.

\subsubsection{Historical decomposition}

The results of the historical decomposition for real output, real money balances, inflation and real stock market prices, over the period 1986:1-2003:1 are reported in Figures 1 and $2 .{ }^{16}$ As shown in Figure 1, two shocks explain the real output cycle, namely the aggregate demand shock and the productivity shock. The importance of the aggregate demand shock is particularly evident for the first part of the sample (1986-1993), pointing to disequilibrium dynamics as the major determinant of output fluctuations. For the second part of the sample (1994-2003)

\footnotetext{
${ }^{15}$ The suggested interpretation for the structural shocks is also supported by the estimated impulse response functions, which are not reported for reasons of space. They are available upon request to the author.

${ }^{16}$ Some experimentation showed that using twenty lags in the historical decomposition was sufficients to achieve a full reconstruction of the cyclical components.
} 
both shocks seem to contribute in equal proportions to shape the cyclical dynamics, pointing therefore to a role also for equilibrium dynamics. ${ }^{17}$ According to the decomposition, the aggregate demand shock is responsible for output falling below potential since 2001:3, while productivity shocks have mitigated the effects of demand shortages, occurred already in 2000, apart from the last three quarters of the sample. Also the liquidity preference shock has contributed to the fall in real output since 2002:3. As shown in Figure 1, the liquidity preference shock is the main determinant of cyclical stock market fluctuations, albeit also productivity shocks and aggregate demand shocks exercise some impact on stock market prices. It is possible to note the speculative nature of the 1987 stock market crash, as well as the persistent overvaluation ${ }^{18}$ of the stock market since 1993, albeit over the period 1999-2001 also productivity shocks seem to have contributed. The most recent phase of economic contraction has been characterised by stock market undervaluation. In fact, real stock market prices would have started to revert back to trend since 2000:4, reaching trend values in 2002:2, and falling below trend afterwards. The liquidity preference shock appears to have been the most important causing factor for the observed phenomena, with all the other shocks, apart from the term structure shock, also contributing to the undervaluation of the stock market. As shown in Figure 2, the liquidity preference shock also explains the current positive deviation of real money balances from trend, while the productivity and the Fisher equation shocks have contributed to the real money balance cycle over all the investigated time span. Since 1999, the productivity shock and the Fisher equation shock have almost compensated each other. Hence, most of the current real money balances hoarding has been determined by the shift to liquidity in investor's preferences, following the stock market crash and to the increased uncertainty surrounding asset allocation, afterwards. ${ }^{19}$ Finally, the inflation cycle can be related to the Fisher parity shock, with the productivity, the aggregate demand and the liquidity shocks also playing some role. The liquidity preference shock, together with the Fisher parity shock, is important to explain the deviations of actual inflation from trend at the end of the sample.

\footnotetext{
${ }^{17}$ We term disequilibrium dynamics the one associated with the transitory innovations, and equilibrium dynamics the one associated with the permanent innovations. See the methodological Appendix.

${ }^{18}$ Overvaluation of the stock market is measured relatively to the trend component determined by productivity shocks.

${ }^{19}$ See $\operatorname{ECB}(2004)$ for similar findings.
} 


\subsection{Simulation analysis}

To assess the response of monetary policy to macroeconomic shocks over the period 1999:1-2003:4, we have employed an unconditional simulation approach, assuming that the short term nominal interest rate is fixed period after period to the level which delivers a given level of the trend inflation rate (the permanent inflation component ${ }^{20}$ ), namely $1 \%, 1.5 \%, 2 \%, 2.5 \%$, and $3 \%$. The simulation is unconditional, since it is carried out period by period disregarding the effects of having implemented the rule in the preceding periods.

Let us consider that at a certain point in time $(t)$ there is a positive deviation of trend inflation $\left(\pi_{t}^{c}\right)$ from the price stability objective $\left(\pi^{*}\right)\left(\pi_{t}^{c}-\pi^{*}>0\right)$. Without lack of generality, suppose that the monetary authority wants to bring the economy onto the aimed price path next period, i.e. at time $(t+1)$. The necessary innovation in core inflation is given by

$$
\psi_{\beta, t+1}=\left(\pi^{*}-\pi_{t}^{c}-\mu_{\pi}\right) / \gamma_{2} .
$$

and the short term nominal interest rate innovation necessary to ensuring the correction in core inflation is given by

$$
b_{F H}(L) y_{F H, t+1}=\theta_{F H}+\Lambda_{F H} \varphi_{t+1},
$$

where $b_{F H}(L), y_{F H, t+1}, \theta_{F H}, \Lambda_{F H}, \boldsymbol{\varphi}_{t+1}$ are the relevant entries in the Fisher parity equation in the restricted VAR representation (RVAR) of the model. The feasibility condition for controlling inflation in our framework depends on the impact of the policy innovation on the Fisher parity disequilibrium given by $\frac{\partial y_{F H, t+1}}{\partial \psi_{\beta, t+1}}=\Lambda_{F H, \beta}<0$.

The required short term nominal interest rate level necessary to achieve price stability in the next period is given by

$$
i_{t+1}=i_{t}+\Lambda_{F H, \beta} \psi_{\beta, t+1} .
$$

In Figure 3 the actual and simulated short term nominal interest rates over the period 1999-2003 are plotted. As can be noted from the plot, the actual interest rate path falls between the two levels of interest rates implied by the stabilisation of the trend inflation rate in the range 1\%-3\%. Moreover, for the most recent period the range would be even stricter (1.5\%-2.5\%). ${ }^{21}$ Hence, despite the adverse

\footnotetext{
${ }^{20}$ See Bagliano et al. (2002).

${ }^{21}$ See also Altavilla and Landolfo (2005) for similar findings concerning the implicit inflation reference value.
} 
macroeconomic developments since 2001, there is no evidence that the definition of price stability adopted by the ECB may have determined a deflationary bias. Moreover, given that the trend inflation rate bears the interpretation of long-run inflation forecast, we do not find any evidence of a failure in anchoring inflation expectations.

\section{Conclusions}

In the paper we have employed a small scale macroeconometric model for the euro-12 area to assess the sources of macroeconomic fluctuations and the ECB monetary policy response over the period 1999-2003. Our assessment points to aggregate demand shortages leading to output falling below potential, also following the burst of the stock market bubble and the associated decline in real stock market prices. A purely financial shock, possibly reflecting investor's uncertainty, would be responsible for the current stock market undervaluation, the latter contributing to depress economic activity. We interpret current developments in excess real money balances as reflecting the effects of the portfolio shift towards monetary assets following the stock market crash in 2000, and the increase in stock market and macroeconomic uncertainty afterwards. The slow down in economic activity and the expectations of persistence of this phenomenon in the medium term may have also contributed to keep the preference of investors biased towards liquidity. Moreover, while the inflation cycle points to excess inflation relatively to trend due to transitory shocks, trend inflation, as measured by the annualised permanent component in the GDP deflator inflation rate, is currently close to $1.5 \%$, suggesting that the monetary accommodation may have been appropriate also to preempt deflationary threats. A simulation exercise, conditional to the recent non favourable macroeconomic context, shows that the current definition of price stability has implied the setting of the policy rate at levels compatible with trend inflation fluctuations in the range 1\%-3\%. Hence, we have not found any evidence supporting the view that the definition of price stability adopted by the ECB has created a deflationary bias or has not allowed a full anchoring in inflation expectations. Actually, as also argued in Bordo and Filardo (2004), the two-pillar strategy may be seen particularly appropriate to manage monetary policy in deflationary environments, given the prominent role, among the various instruments, nominal monetary base growth will have in such circumstances. 


\section{Appendix 1: The long-run Fisher relationship}

Structural change in the real ex-post interest rate has been investigated by means of a Markov switching model (Hamilton, 1989). This approach allows to detect structural change, without a priori assumptions concerning the location and number of break points. The estimated equation can be written as

$$
i_{t}-\pi_{t}=r s_{t}=\alpha\left(s_{t}\right)+\varepsilon_{i, t},
$$

where the component $\alpha\left(s_{t}\right)$ capture time variation in the mean process, assuming a different value according to the regime. ${ }^{22}$

The Markov-switching model has been selected according to specification tests and LR tests, with p-values computed as in Davies (1987) to account for the non standard asymptotic distribution of the LR test. According to the LR and specification tests a two-regime model for the intercept, with a first order autoregressive term, could be selected, suggesting that the persistence in the ex-post real interest rate is not fully explained by the break process only. This parsimonious model is characterised by residuals which do not show any evidence of serial correlation, eteroschedasticity or non normality ${ }^{23}$, and can be preferred to a three-regime $\mathrm{AR}(1)$ model and to the linear $\mathrm{AR}(1)$ model on the basis of the LR test. ${ }^{24}$ The estimated annualised mean component is $2.13 \%(0.173 \%)$ in the low risk premium regime (low real interest rate regime) and $5.68 \%(0.351 \%)$ in the high risk premium regime (high real interest rate regime). In Figure 4 the estimated smoothed probabilities are plotted. As is shown in the plot, the high real interest rate regime ends in 1995:4, suggesting that the fall in the risk premium anticipated the introduction of the common monetary policy.

\footnotetext{
${ }^{22}$ In our application $s_{t}=1,2$, i.e. high and low inflation premium regime.

${ }^{23}$ The p-value of the tests are $0.1176,0.3765$, and 0.6447 , respectively.

${ }^{24}$ The p-values for the LR linearity test are equal to 0.0730 and 0.0552 for the three-regime
}

and the two-regime models, suggesting that the two-regime model should be preferred to the three-regime model. Moreover the two-regime model should be preferred to the linear model, albeit the null of linearity is not rejected at a significance level lower than $6 \%$. However, evidence of instability in the mean component are also provided by the Hansen instability test: the test statistic is equal to 0.505 , allowing to reject the null of stable intercept at the $5 \%$ significance level. Moreover, the estimated means in the two regimes are statistically different. The test for the equality of the two means is equal to 9.079 , with p-value equal to 0 . 


\section{Appendix 2: econometric methodology}

The standard VECM representation of the model, controlling for a linear trend in the variables in levels, can be written as

$$
\Pi^{*}(L) \Delta \mathbf{x}_{t}=\boldsymbol{\nu}+\Pi \mathbf{x}_{t-1}+\varepsilon_{t}
$$

where $\mathbf{x}_{t}$ is the vector of $n I(1)$ cointegrated variables of interest, $\boldsymbol{\nu}$ is the vector of intercept terms, $\varepsilon_{t} \sim N I D(\mathbf{0}, \Sigma), \Pi(L)=\mathbf{I}_{n}-\sum_{i=1}^{p} \Pi_{i} L^{i}, \Pi=-\Pi(1), \Pi^{*}(L)=$ $\mathbf{I}_{n}-\sum_{i=1}^{p-1} \Pi_{i}^{*} L^{i}$ and $\Pi_{i}^{*}=-\sum_{j=i+1}^{p} \Pi_{j}(i=1, \ldots, p-1)$. If there are $0<r<n$ cointegration relationships among the variables, $\Pi(1)$ is of reduced rank $r$ and can be expressed as the product of two $(n \times r)$ matrices: $\Pi(1)=\boldsymbol{\alpha} \boldsymbol{\beta}^{\prime}$, where $\boldsymbol{\beta}$ contains the cointegrating vectors, such that $\boldsymbol{\beta}^{\prime} \mathbf{x}_{t}$ are stationary linear combinations of the $I(1)$ variables, and $\boldsymbol{\alpha}$ is the matrix of factor loadings. Following Bagliano et al. (2003), when one of the cointegrating vectors contains a switching intercept modelled by dummy variables (i.e. the $r$ th vector), it is possible to rewrite the $\boldsymbol{\beta}$ matrix as

$$
\overline{\boldsymbol{\beta}}=\left(\begin{array}{rr}
\boldsymbol{\beta} & \\
\mathbf{0}_{q \times(r-1)} & \boldsymbol{\beta}_{q, r}^{*}
\end{array}\right)
$$

where $\boldsymbol{\beta}^{*}=\left[\begin{array}{ll}\mathbf{0}_{q \times(r-1)} & \boldsymbol{\beta}_{q, r}^{*}\end{array}\right]$ and $\boldsymbol{\beta}_{q, r}^{*}$ is the $q \times 1$ subvector which contains the parameters of the $q$ deterministic variables in the $r$ th cointegrating vector. If there are $q$ regimes, $q-1$ regimes may be normalised relatively to the $q$ th regime. This amounts to measure the switches relatively to a constant intercept term, requiring therefore a constant term and $q-1$ intervention dummies. The VECM representation can be rewritten as

$$
\Pi^{*}(L) \Delta \mathbf{x}_{t}=\boldsymbol{\nu}+\boldsymbol{\alpha} \overline{\boldsymbol{\beta}}^{\prime} \overline{\mathbf{x}}_{t-1}+\varepsilon_{t}
$$

where $\overline{\mathbf{x}}_{t}=\left[\begin{array}{lll}\mathbf{x}_{t}^{\prime} & 1 & \mathbf{d}_{t}^{\prime}\end{array}\right]^{\prime}$ and $\mathbf{d}_{t}$ is a $(q-1) \times 1$ subvector including the $q-1$ intervention dummies, or in the estimable form

$$
\Pi^{*}(L) \Delta \mathbf{x}_{t}=\boldsymbol{\nu}^{*}+\boldsymbol{\alpha} \boldsymbol{\beta}_{2}^{* \prime} \mathbf{d}_{t-1}+\boldsymbol{\alpha} \boldsymbol{\beta}^{\prime} \mathbf{x}_{t-1}+\varepsilon_{t},
$$


where $\boldsymbol{\nu}^{*}=\boldsymbol{\nu}+\boldsymbol{\alpha} \boldsymbol{\beta}_{1}^{* \prime}, \boldsymbol{\beta}_{1}^{*}$ and $\boldsymbol{\beta}_{2}^{*}$ denote respectively the first and the last $q-1$ elements in $\boldsymbol{\beta}^{*}$. In practice the model can be estimated leaving the deterministic components unrestricted.

The restricted vector autoregressive representation (RVAR) (Mellander, Vredin and Warne, 1992; Warne, 1993) can be written as

$$
\mathbf{B}(L) \mathbf{y}_{t}=\boldsymbol{\theta}+\boldsymbol{\delta} \mathbf{d}_{t-1}+\boldsymbol{\eta}_{t}
$$

where $\mathbf{B}(L)=\mathbf{T}\left[\Pi^{*}(L) \mathbf{T}^{-1} \mathbf{D}(L)+\boldsymbol{\alpha}^{*} L\right], \mathbf{y}_{t}=\mathbf{D}_{\perp}(L) \mathbf{T} \mathbf{x}_{t}, \boldsymbol{\theta}=\mathbf{T} \boldsymbol{\nu}, \boldsymbol{\delta}=\mathbf{T} \boldsymbol{\alpha} \boldsymbol{\beta}_{\mathbf{2}}^{* \prime}, \boldsymbol{\eta}_{t}=$ $\mathbf{T} \varepsilon_{\mathbf{t}}, \mathbf{T}=\left[\begin{array}{ll}\boldsymbol{\beta}_{\perp}^{\prime} & \boldsymbol{\beta}\end{array}\right]^{\prime}, \boldsymbol{\alpha}^{*}=\left[\begin{array}{ll}\mathbf{0} & \boldsymbol{\alpha}\end{array}\right], \mathbf{D}(L)$ and $\mathbf{D}_{\perp}(L)$ are polynomial matrices defined by

$$
\mathbf{D}(L)=\left[\begin{array}{cc}
\mathbf{I}_{k} & \mathbf{0} \\
\mathbf{0} & (1-L) \mathbf{I}_{r}
\end{array}\right], \mathbf{D}_{\perp}(L)=\left[\begin{array}{cc}
(1-L) \mathbf{I}_{k} & \mathbf{0} \\
\mathbf{0} & \mathbf{I}_{r}
\end{array}\right] .
$$

Following Mellander, Vredin and Warne (1992) and Warne (1993), the RVAR can be inverted to obtain the common trends representation of Stock and Watson (1988), which, in structural form, can be written as

$$
\begin{aligned}
\mathbf{x}_{t} & =\mathbf{x}_{0}+\boldsymbol{\mu} t+\sum_{j=1}^{q-1} \boldsymbol{\mu}_{j}^{*} \mathbf{d}_{j, t-1} t+\Gamma(1) \sum_{j=0}^{t-1} \boldsymbol{\varphi}_{t-j}+\Gamma^{*}(L) \boldsymbol{\varphi}_{t} \\
& =\mathbf{x}_{0}+\boldsymbol{\mu} t+\sum_{j=1}^{q-1} \boldsymbol{\mu}_{j}^{*} \mathbf{d}_{j, t-1} t+\Gamma_{g} \sum_{j=0}^{t-1} \boldsymbol{\psi}_{t-j}+\Gamma^{*}(L) \boldsymbol{\varphi}_{t},
\end{aligned}
$$

where $\boldsymbol{\mu}=\Gamma_{g} \boldsymbol{\nu}^{*}, \boldsymbol{\mu}^{*}=\Gamma_{g} \boldsymbol{\alpha} \boldsymbol{\beta}_{2}^{* \prime}, \mathbf{d}_{j, t}$ denotes the $j$ th column of $\mathbf{d}_{t}, \boldsymbol{\varphi}_{t} \equiv\left[\begin{array}{ll}\boldsymbol{\psi}_{t} & \boldsymbol{v}_{t}\end{array}\right]^{\prime} \sim$ I.I.D. $\left(\mathbf{0}, \mathbf{I}_{n}\right)$, with $\boldsymbol{\psi}_{t}$ and $\boldsymbol{v}_{t}$ subvectors of structural shocks of $k$ and $r$ elements respectively, $\varepsilon_{t}=\Gamma_{0} \varphi_{t}$, and $\Gamma(1)=\sum_{j=0}^{\infty} \Gamma_{j}, \Gamma^{*}(L)=\sum_{j=0}^{\infty} \Gamma_{j}^{*} L^{j}, \Gamma_{j}^{*}=-$ $\sum_{i=j+1}^{\infty} \Gamma_{i}$, where $\Gamma_{i}$ are matrices of parameters in the structural Wold vector moving average (VMA) representation. The existence of $r$ cointegrating vectors implies that the long-run matrix $\Gamma(1)$ has rank $n-r \equiv k$ and $\boldsymbol{\beta}^{\prime} \Gamma(1)=\mathbf{0}$.

In order to identify the elements of $\boldsymbol{\psi}_{t}$ as the permanent shocks and the elements of $\boldsymbol{v}_{t}$ as transitory disturbances, only the disturbances in $\boldsymbol{\psi}_{t}$ should be allowed to have long-run effects on (at least some of) the variables in $\mathbf{x}_{t}$. Hence, $\Gamma(1)=\left[\begin{array}{ll}\Gamma_{g} & 0\end{array}\right]$, being $\Gamma_{g}$ a submatrix of dimension $n \times k$.

In the structural common trends representation only $k$ shocks (the permanent shocks $\boldsymbol{\psi}_{t}$ ) are cumulated in the trend component. The behaviour of the variables 
in $\mathbf{x}_{t}$ induced by permanent disturbances may then be computed as

$$
\mathbf{x}_{t}^{p}=\mathbf{x}_{0}+\boldsymbol{\mu} t+\sum_{j=1}^{q-1} \boldsymbol{\mu}_{j}^{*} \mathbf{d}_{j, t-1} t+\Gamma_{g} \sum_{j=0}^{t-1} \boldsymbol{\psi}_{t-j},
$$

while the cyclical components is

$$
\mathbf{x}_{t}^{c}=\Gamma^{*}(L) \boldsymbol{\varphi}_{t}
$$

This is the Beveridge-Nelson-Stock-Watson trend-cycle decomposition of $\mathbf{x}_{t}=$ $\mathbf{x}_{t}^{p}+\mathbf{x}_{t}^{c}$. Note that the cyclical component is determined by all the innovations in the system, both permanent and transitory. This implies that permanent innovations also induce transitory dynamics.

Identification of the shocks To identify the common trends model it is necessary to find a matrix $\Gamma_{0}$, such that it can be uniquely determined from the parameters of the VECM model in (6.2), where the variance covariance matrix of $\Gamma_{0}^{-1} \varepsilon_{t}=\varphi_{t}$ is diagonal with non zero entries, and the long-run impact matrix is $\Gamma(1)=\left[\begin{array}{ll}\Gamma_{g} & 0\end{array}\right]$.

By rewriting the mapping from the reduced form disturbances to the structural disturbances as

$$
\Gamma_{0}^{-1} \varepsilon_{t}=\boldsymbol{\varphi}_{t} \Leftrightarrow\left[\begin{array}{c}
\mathbf{G} \\
\mathbf{H}
\end{array}\right] \varepsilon_{t}=\left[\begin{array}{c}
\psi_{t} \\
\boldsymbol{v}_{t}
\end{array}\right]
$$

it can be noticed that through the $(k \times n)$ matrix $\mathbf{G}$ the reduced form disturbances are mapped into permanent disturbances, and through the $(r \times n)$ matrix $\mathbf{H}$ the reduced form disturbances are mapped into transitory disturbances.

Following Warne (1993), the matrix $\mathbf{G}$ can be estimated as

$$
\mathbf{G}=\left(\Gamma_{g}^{\prime} \Gamma_{g}\right)^{-1} \Gamma_{g}^{\prime} \mathbf{C}(1)
$$

where $\mathbf{C}(1)$ is the long-run impact matrix in the reduced form Wold VMA representation, while the matrix $\mathbf{H}$ as

$$
\mathbf{H}=\mathbf{Q}^{-1} \boldsymbol{\zeta}^{\prime} \Sigma^{-1}
$$

where $\boldsymbol{\zeta}=\boldsymbol{\alpha}(\mathbf{U} \boldsymbol{\alpha})^{-1}, \mathbf{U}$ is a matrix chosen in such a way that $\mathbf{U} \boldsymbol{\alpha}$ is non singular, and the $(r \times r)$ matrix $\mathbf{Q}$ is such that $E\left[\boldsymbol{v}_{t} \boldsymbol{v}_{t}^{\prime}\right]=\mathbf{I}_{r}$. In practice the matrix $\mathbf{Q}$ can be obtained from the Choleski decomposition of $\left(\boldsymbol{\zeta}^{\prime} \Sigma^{-1} \boldsymbol{\zeta}\right)^{-1}$. 
Note that the estimation of the above matrices requires the imposition of additional restrictions. In fact, to estimate the $(n \times k)$ matrix $\Gamma_{g}$, we need (at least) $n k$ restrictions on its elements. Cointegration implies $\boldsymbol{\beta}^{\prime} \Gamma_{g}=\mathbf{0}$, yielding $k r$ linear restrictions. Additional $k(k+1) / 2$ restrictions on the elements of $\Gamma_{g}$ are provided by assuming $E\left(\boldsymbol{\psi}_{t} \boldsymbol{\psi}_{t}^{\prime}\right)=\mathbf{I}_{k}$. The remaining $k(k-1) / 2$ restrictions needed for (exact) identification of $\Gamma_{g}$ have to be derived from economic theory. Moreover, the estimation of the $(r \times n)$ matrix $\mathbf{H}$ requires at least $n r$ restrictions on its elements. This is accomplished by the imposition of $r(r-1) / 2$ additional restrictions, suggested by economic theory, on the $(r \times r)$ matrix $\boldsymbol{\zeta}$, since the remaining $k r+r(r+1) / 2$ restrictions necessary for exact identification are provided by the orthogonality conditions $E\left[\boldsymbol{\psi}_{t} \boldsymbol{v}_{t}^{\prime}\right]=\mathbf{0}$ and $E\left[\boldsymbol{v}_{t} \boldsymbol{v}_{t}^{\prime}\right]=\mathbf{I}_{r}$.

By noting that $\Sigma=\Gamma_{0} \Gamma_{0}^{\prime}$, we have that $\Gamma_{0}=\Sigma\left(\Gamma_{0}^{\prime}\right)^{-1}=\left[\begin{array}{ll}\Sigma \mathbf{G}^{\prime} & \Sigma \mathbf{H}^{\prime}\end{array}\right]$. Thus, the contemporaneous impact matrix can be written as

$$
\Gamma_{0}=\left[\Sigma \mathbf{C}(1)^{\prime} \Gamma_{g}\left(\Gamma_{g}^{\prime} \Gamma_{g}\right)^{-1} \quad \boldsymbol{\zeta}\left(\mathbf{Q}^{-1}\right)^{\prime}\right]
$$

Cyclical dynamics An important property of the Beveridge-Nelson-StockWatson decomposition is that the cyclical component $\mathbf{x}_{t}^{c}$ is explained not only by transitory shocks, but also by permanent shocks. Proietti (1997) has proposed a methodology to disentangle in cyclical fluctuations the contribution of permanent shocks from the effect of transitory disturbances. Following Cassola and Morana (2002), a similar decomposition of the cycles can be obtained by rewriting the vector of cyclical components as

$$
\mathbf{x}_{t}^{c}=\Gamma^{*}(L) \boldsymbol{\varphi}_{t}=\Gamma_{1}^{*}(L) \boldsymbol{\psi}_{t}+\Gamma_{2}^{*}(L) \boldsymbol{v}_{t}
$$

The vector $\Gamma_{1}^{*}(L) \boldsymbol{\psi}_{t}$ gives the contribution of permanent innovations to the overall cycle (dynamics along the attractor), while the vector $\Gamma_{2}^{*}(L) \boldsymbol{v}_{t}$ measures the contribution of the transitory innovations to the overall cycle (dynamics towards the attractor). The adjustment dynamics have the error correction process as generator, and, therefore, are disequilibrium fluctuations, while the dynamics along the attractor may be related to the overshooting of the variables to the permanent innovations, i.e. they are the transitional dynamics which take place after a shock to the common trend hits the economy. Since along the attractor the cointegration relationships are satisfied, the dynamics along the attractor are equilibrium fluctuations. 


\section{References}

[1] Alesina, A., O. Blanchard, J. Gali, F. Giavazzi and H. Hulig, 2001, Defining a Macroeconomic Framework for the Euro Area, Monitoring the European Central Bank 3, CEPR, London.

[2] Altavilla, C. and L. Landolfo, 2005, Do Central Banks Act Symmetrically? Empirical Evidence from the ECB and the Bank of England, Applied Economics, 37, 507-19.

[3] Bagliano, F.C., R. Golinelli and C. Morana, 2003, Inflation Modelling in the Euro Area, in Fiscal Policies, Monetary Policies and Labour Markets. Key Aspects of European Macroeconomic Policies after Monetary Unification, R. Beetsma, C. Favero, A. Missale, V.A. Muscatelli, P. Natale and P. Tirelli (eds), Cambridge University Press.

[4] Bagliano, F.C., R. Golinelli and C. Morana, 2002, Core Inflation in the Euro Area, Applied Economics Letters, 9(6), 353-57.

[5] Blanchard, O.J., 1981, Output, the Stock Market, and Interest Rates, American Economic Review, 71, 132-143.

[6] Bordo, M.D. and A. Filardo, 2004, Deflation and Monetary Policy in a Historical Perspective: Remembering the Past or Being Condmened to Repeat It?, NBER Working Paper Series, no.10833.

[7] Brand C. and N. Cassola, 2004, A Money Demand System for Euro Area M3, Applied Economics, 36, 817-38.

[8] Bruggeman A., P. Donati and A. Warne, 2003, Is the Demand for Euro Area M3 Stable?, manuscript, European Central Bank.

[9] Cassola, N. and C. Morana, 2004, Monetary Policy and the Stock Market in the Euro Area, Journal of Policy Modelling, 26(3), 387-99.

[10] Cassola, N. and C. Morana, 2002, Monetary Policy and the Stock Market in the Euro Area, European Central Bank Working Paper Series, 2002/119.

[11] Davies, R.B., 1987, Hypothesis Testing when a Nuisance Parameter is Present only Under the Alternative, Biometrika, 74(1), 33-43. 
[12] ECB, 2003, The Outcome of the ECB's Evaluation of its Monetary Policy Strategy, ECB Monthly Bulletin, June, 79-92.

[13] ECB, 2004, Monetary Analysis in Real Time, ECB Monthly Bulletin, October, 43-66.

[14] Ericsson, N.R. and J.C. MacKinnon, 2002, Distribution of Error Correction Tests for Cointegration, Econometrics Journal, 5, 285-318.

[15] Fitoussi, J.-P. and J. Creel, 2002, How to Reform the European Central Bank, Centre for European Reform, London.

[16] Fitoussi, J.-P., 2003, What First Assessment can be Made of the Monetary Strategy since 1999?, briefing paper for the Committee of Economic and Monetary Affairs of the European Parliament.

[17] Granger, C.W.J. and N. Haldrup, 1997, Separation in Cointegrated Systems and Persistent-Transitory Decompositions, Oxford Bulletin of Economics and Statistics, 59(4), 449-63.

[18] Gros, D., J. Jimeno, C. Monticelli, G. Tabellini and N. Thygesen, 2001, Testing the Speed Limit for Europe, 3rd Report of the CEPS Macroeconomic Policy Group, June.

[19] Hamilton, J.D., 1989, A New Approach to the Economic Analysis of Non Stationary Time Series and the Business Cycle, Econometrica, 57, 357-84.

[20] IMF, 2002, Concluding Statement of the IMF Mission on the Economic Policies of the Euro Area - in the Context of the 2002 Article IV Consultation Discussions with the Euro Area Countries, July 12, 2002.

[21] Johansen, S., 1988, Statistical Analysis of Cointegrating Vectors, Journal of Economic Dynamics and Control, 12, 231-54.

[22] Konishi, T. and C.W.J. Granger, 1992, Separation in Cointegrated Systems, mimeo, University of California, San Diego.

[23] Mellander, E., A. Vredin and A. Warne, 1992, Stochastic Trends and Economic Fluctuations in a Small Open Economy, Journal of Applied Econometrics, 7, 369-94. 
[24] Morana, C., 2004, The Japanese Deflation: Has It Had Real Effects? Could it Have Been Avoided?, Applied Economics, forthcoming.

[25] Morana, C., 2005, A Structural Common Factor Approach to Core Inflation Estimation and Forecasting, Applied Economics Letters, forthcoming.

[26] Proietti, T. , 1997, Short-Run Dynamics in Cointegrated Systems, Oxford Bulletin of Economics and Statistics, 59, 3, 403-422.

[27] Sauch, J.-G., 2004, Partial Indexation and Inflation Dynamics, Applied Economics Letters, 11(13), 827-32.

[28] Stock, J.H. and M.W. Watson, 1988, Testing for Common Trends, Journal of the American Statistical Association, 83, 1097-107.

[29] Svensson, L.E.O., 2002a, A Reform of Eurosystem's Monetary Policy Strategy is Increasingly Urgent?, briefing paper for the Committee of Economic and Monetary Affairs of the European Parliament.

[30] Svensson, L.E.O., 2002b, A Good Thing Could Happen at the ECB: An Improvement of the Eurosystem's Defintion of Price Stability, manuscript, University of Princeton.

[31] Svensson, L.E.O., 2003, How Should the Eurosystem Reform its Monetary Strategy?, briefing paper for the Committee of Economic and Monetary Affairs of the European Parliament.

[32] von Hagen, J. and B. Hofmann, 2004, Macroeconomic Implications of Low Inflation in the Euro Area, North American Journal of Economics and Finance, $15,5-23$.

[33] Warne, A., 1993, A Common Trends Model: Identification, Estimation and Inference, Seminar Paper No. 555, IIES, Stockholm University.

[34] Wyplosz, C., 2003, The New Eurosystem, briefing paper for the Committee of Economic and Monetary Affairs of the European Parliament. 
Table 1

Cointegration analysis

Cointegration tests

\begin{tabular}{ccccccc}
\hline \hline Eigenvalue: & 0.3602 & 0.3316 & 0.2064 & 0.1711 & 0.0672 & 0.0035 \\
Hypothesis: & $r=0$ & $r \leq 1$ & $r \leq 2$ & $r \leq 3$ & $r \leq 4$ & $r \leq 5$ \\
$\lambda_{T R A C E}$ & 124.7 & 83.21 & 45.74 & 24.24 & 6.79 & 0.32 \\
$90 \%$ crit. value & 79.19 & 55.89 & 36.59 & 23.43 & 7.68 & 2.69 \\
$95 \%$ crit. value & 83.66 & 59.76 & 39.86 & 26.06 & 9.34 & 3.78 \\
$99 \%$ crit. value & 93.09 & 76.02 & 45.92 & 30.91 & 12.87 & 6.52 \\
\hline \hline
\end{tabular}

$r$ denotes the number of valid cointegrating vectors;

Estimated cointegrating vectors

( $\beta^{\prime}$ matrix; standard errors in parentheses)

\begin{tabular}{cccccc}
\hline \hline$y$ & $r m$ & $f$ & $i$ & $l$ & $\pi$ \\
\hline \hline-3.524 & & 1 & & & \\
$(0.461)$ & & $(-)$ & & & \\
-1.475 & 1 & & & & \\
$(0.032)$ & $(-)$ & & & & \\
& & & -1 & 1 & \\
& & & $(-)$ & $(-)$ & \\
& & & 1 & & -1 \\
& & & $(-)$ & & $(-)$ \\
\hline \hline
\end{tabular}

Estimated factor loadings matrix

( $\alpha$ matrix; standard errors in parentheses)

\begin{tabular}{c|llll}
\hline \hline$\Delta y$ & 0.009 & 0.049 & 0.007 & 0.003 \\
& $(0.002)$ & $(0.03)$ & $(0.003)$ & $(0.002)$ \\
$\Delta r m$ & -0.047 & 0.786 & 0.040 & 0.044 \\
& $(0.035)$ & $(0.438)$ & $(0.039)$ & $(0.031)$ \\
$\Delta f$ & -0.001 & -0.058 & -0.003 & -0.005 \\
& $(0.002)$ & $(0.026)$ & $(0.002)$ & $(0.002)$ \\
$\Delta i$ & -0.069 & -2.865 & 0.102 & -0.141 \\
& $(0.057)$ & $(0.722)$ & $(0.064)$ & $(0.051)$ \\
$\Delta l$ & -0.038 & -0.343 & -0.142 & -0.124 \\
& $(0.047)$ & $(0.593)$ & $(0.053)$ & $(0.042)$ \\
$\Delta \pi$ & 0.152 & 1.726 & 0.222 & 0.279 \\
& $(0.116)$ & $(1.464)$ & $(0.131)$ & $(0.102)$ \\
\hline \hline
\end{tabular}

22 


\section{Table 2}

\section{The estimated common trends model}

\section{Panel A: Long-run effects of permanent shocks (\%) (matrix $\Gamma_{g}$ )} (simulated standard errors in parentheses, annualised values)

\begin{tabular}{c|lc}
\hline \hline Variable & \multicolumn{2}{|c}{ Shock } \\
& $\psi_{\theta}$ & $\psi_{\beta}$ \\
\hline \hline \multirow{2}{*}{$y$} & 0.406 & - \\
& $(0.207)$ & \\
$r m$ & 0.599 & - \\
& $(0.306)$ & \\
$f$ & 1.430 & - \\
& $(0.731)$ & \\
$i$ & -0.118 & 0.395 \\
& $(0.261)$ & $(0.163)$ \\
$l$ & -0.118 & 0.395 \\
& $(0.261)$ & $(0.163)$ \\
$\pi$ & -0.118 & 0.395 \\
& $(0.261)$ & $(0.163)$ \\
\hline \hline
\end{tabular}

Panel B: Contemporaneous impact of structural shocks (\%) (matrix $\left.\Gamma_{0}\right)$

(simulated standard errors in parentheses, annualised values)

\begin{tabular}{c|l|l|llll}
\hline \hline Variable & & & \multicolumn{3}{|c}{ Shock } & \\
& $\psi_{\theta}$ & $\psi_{\beta}$ & $v_{T S}$ & $v_{S M}$ & $v_{A D}$ & $v_{F H}$ \\
\hline \hline \multirow{2}{*}{$y$} & 0.046 & 0.001 & 0.0 & 0.0 & 0.401 & 0.072 \\
& $(0.096)$ & $(0.091)$ & $(-)$ & $(-)$ & $(0.045)$ & $(0.060)$ \\
& 0.250 & 0.097 & 0.0 & 0.168 & 0.024 & -0.155 \\
& $(0.084)$ & $(0.087)$ & $(-)$ & $(0.073)$ & $(0.074)$ & $(0.057)$ \\
$f$ & 1.609 & 2.364 & 0.023 & -5.245 & 0.852 & -0.245 \\
& $(1.651)$ & $(1.840)$ & $(2.362)$ & $(1.617)$ & $(1.162)$ & $(1.066)$ \\
$i$ & -0.211 & 0.175 & -0.211 & 0.052 & 0.096 & -0.162 \\
& $(0.106)$ & $(0.079)$ & $(0.233)$ & $(0.127)$ & $(0.082)$ & $(0.069)$ \\
$l$ & -0.151 & 0.155 & 0.109 & 0.086 & 0.068 & -0.181 \\
& $(0.095)$ & $(0.066)$ & $(0.063)$ & $(0.097)$ & $(0.071)$ & $(0.049)$ \\
$\pi$ & -0.359 & 0.454 & 0.0 & 0.0 & 0.0 & 0.530 \\
& $(0.164)$ & $(0.151)$ & $(-)$ & $(-)$ & $(-)$ & $(0.084)$ \\
\hline \hline
\end{tabular}


Table 3

The estimated common trends model

Panel A: Forecast error variance decomposition (short term)

\begin{tabular}{c|cccccccccccc}
\hline \hline & \multicolumn{1}{|c}{1 quarter } & \multicolumn{1}{c}{ 1 year } \\
& $\psi_{\theta}$ & $\psi_{\beta}$ & $v_{T S}$ & $v_{S M}$ & $v_{A D}$ & $v_{F H}$ & $\psi_{\theta}$ & $\psi_{\beta}$ & $v_{T S}$ & $v_{S M}$ & $v_{A D}$ & $v_{F H}$ \\
\hline \hline$y$ & 0.01 & 0.00 & 0.00 & 0.00 & 0.96 & 0.03 & 0.04 & 0.08 & 0.02 & 0.02 & 0.82 & 0.02 \\
$r m$ & 0.50 & 0.08 & 0.04 & 0.23 & 0.01 & 0.19 & 0.65 & 0.02 & 0.01 & 0.27 & 0.00 & 0.05 \\
$f$ & 0.07 & 0.15 & 0.00 & 0.75 & 0.02 & 0.00 & 0.20 & 0.08 & 0.01 & 0.65 & 0.04 & 0.01 \\
$i$ & 0.28 & 0.19 & 0.28 & 0.02 & 0.06 & 0.17 & 0.16 & 0.47 & 0.09 & 0.00 & 0.19 & 0.09 \\
$l$ & 0.22 & 0.23 & 0.11 & 0.07 & 0.05 & 0.32 & 0.22 & 0.44 & 0.06 & 0.02 & 0.11 & 0.15 \\
$\pi$ & 0.21 & 0.33 & 0.00 & 0.00 & 0.00 & 0.46 & 0.22 & 0.51 & 0.01 & 0.03 & 0.00 & 0.23 \\
\hline \hline
\end{tabular}

Panel B: Forecast error variance decomposition (medium term)

\begin{tabular}{c|cccccccccccc}
\hline \hline & \multicolumn{1}{|c}{3 year } & \multicolumn{1}{c}{5 year } \\
& $\psi_{\theta}$ & $\psi_{\beta}$ & $v_{T S}$ & $v_{S M}$ & $v_{A D}$ & $v_{F H}$ & $\psi_{\theta}$ & $\psi_{\beta}$ & $v_{T S}$ & $v_{S M}$ & $v_{A D}$ & $v_{F H}$ \\
\hline \hline$y$ & 0.41 & 0.06 & 0.02 & 0.07 & 0.40 & 0.05 & 0.64 & 0.03 & 0.01 & 0.05 & 0.23 & 0.03 \\
$r m$ & 0.71 & 0.01 & 0.01 & 0.18 & 0.02 & 0.07 & 0.83 & 0.01 & 0.01 & 0.10 & 0.02 & 0.04 \\
$f$ & 0.42 & 0.04 & 0.01 & 0.44 & 0.03 & 0.07 & 0.46 & 0.04 & 0.01 & 0.38 & 0.04 & 0.06 \\
$i$ & 0.17 & 0.55 & 0.04 & 0.01 & 0.20 & 0.03 & 0.14 & 0.64 & 0.03 & 0.01 & 0.15 & 0.03 \\
$l$ & 0.20 & 0.63 & 0.02 & 0.02 & 0.06 & 0.06 & 0.17 & 0.71 & 0.02 & 0.02 & 0.04 & 0.04 \\
$\pi$ & 0.20 & 0.67 & 0.00 & 0.02 & 0.01 & 0.10 & 0.16 & 0.75 & 0.00 & 0.01 & 0.01 & 0.07 \\
\hline \hline
\end{tabular}

Panel C: Forecast error variance decomposition (long term)

\begin{tabular}{c|ccc}
\hline \hline Variable & \multicolumn{3}{|c}{$\infty$} \\
& $\psi_{\theta}$ & $\psi_{\beta}$ & $v_{\text {joint }}$ \\
\hline \hline$y$ & 1 & 0.0 & 0.0 \\
$r m$ & 1 & 0.0 & 0.0 \\
$f$ & 1 & 0.0 & 0.0 \\
$i$ & 0.08 & 0.92 & 0.0 \\
$l$ & 0.08 & 0.92 & 0.0 \\
$\pi$ & 0.08 & 0.92 & 0.0 \\
\hline \hline
\end{tabular}



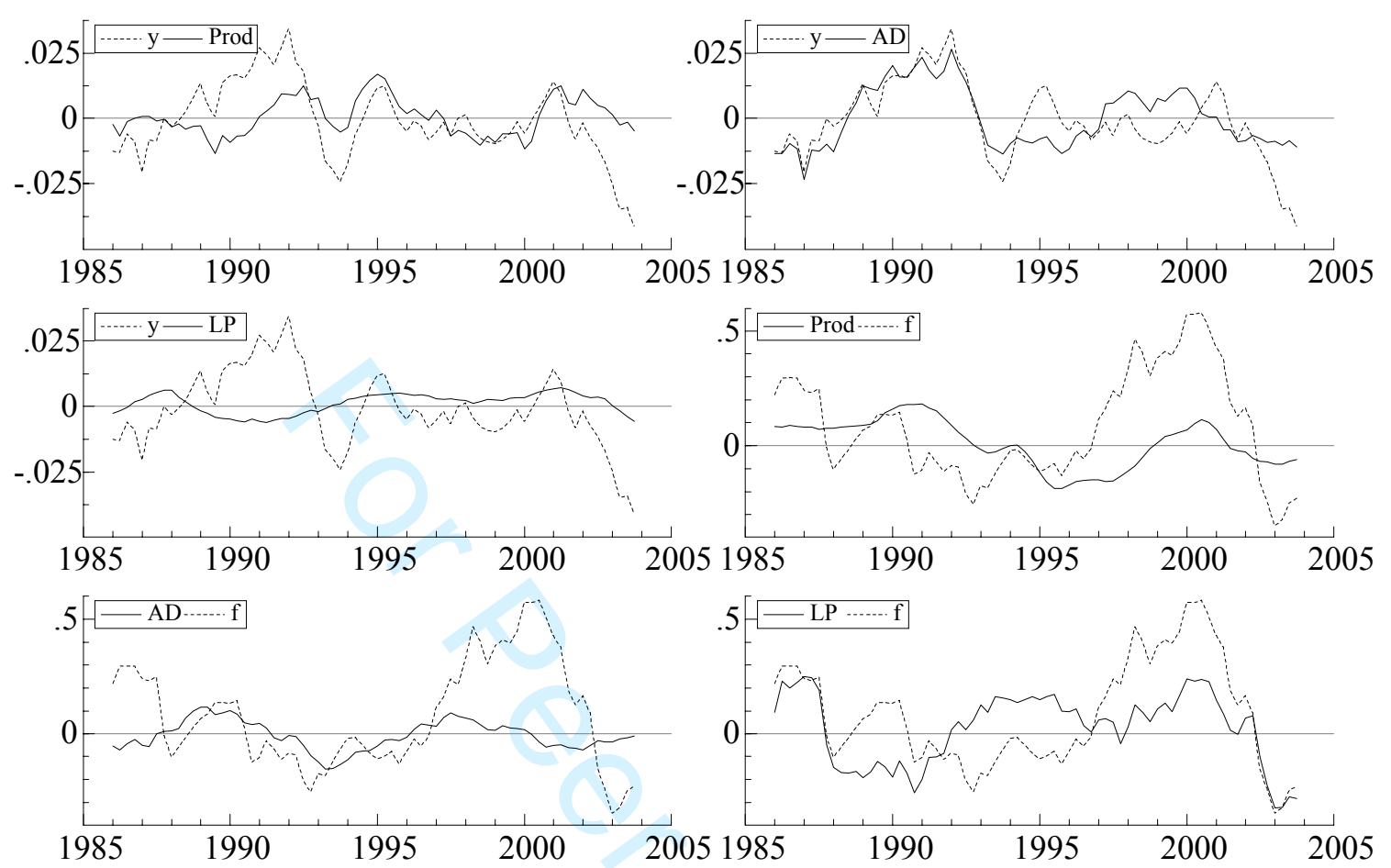

Figure 1: Historical decomposition of output cycle (y) and stock market cycle (f): productivity shock (Prod), liquidity preference shock (LP), aggregate demand shock (AD). 

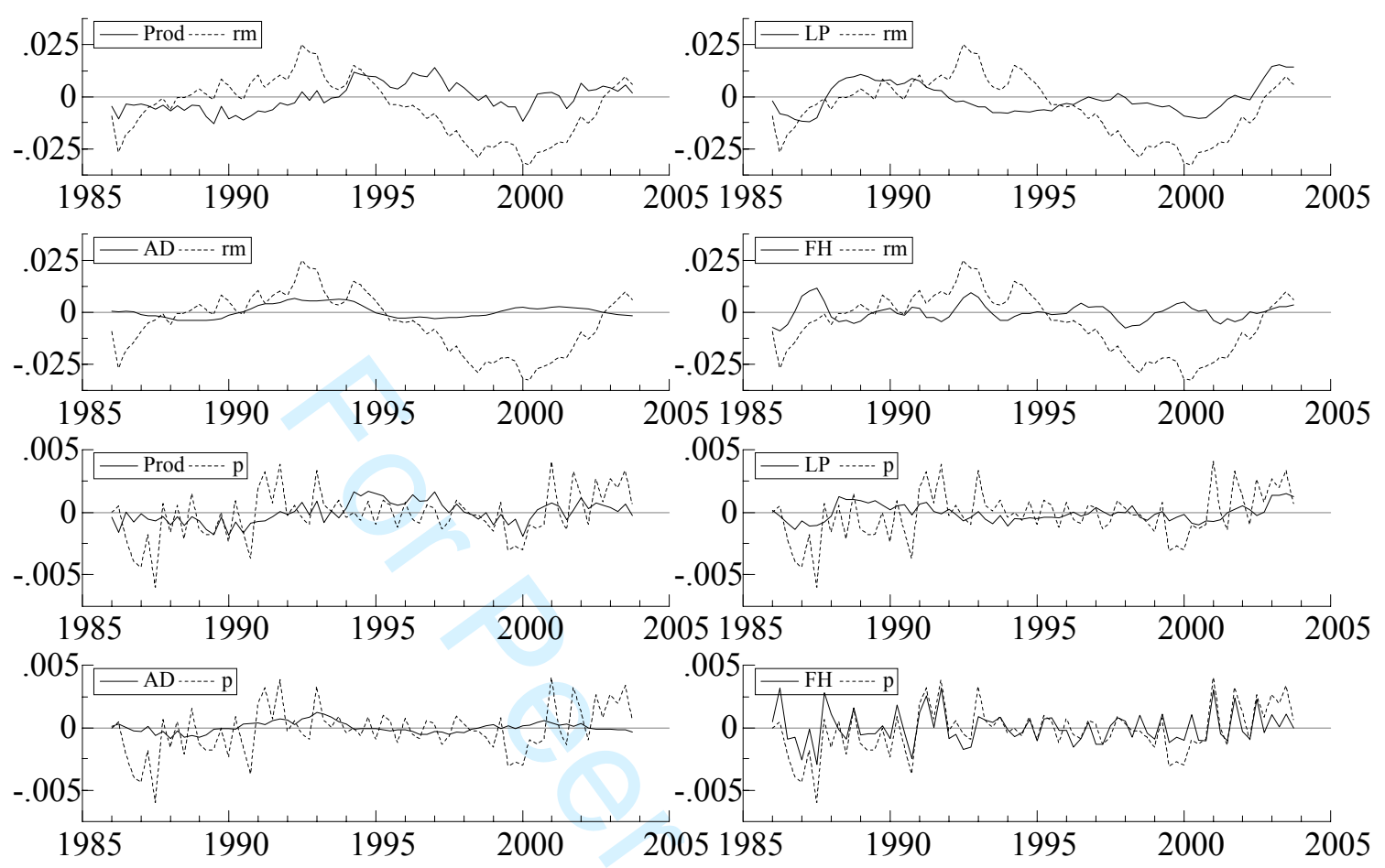

Figure 2: Historical decomposition of real money balances cycle (rm) and inflation cycle $(\mathrm{p})$ : productivity shock (Prod), liquidity preference shock (LP), aggregate demand shock (AD), Fisher equation shock (FH). 


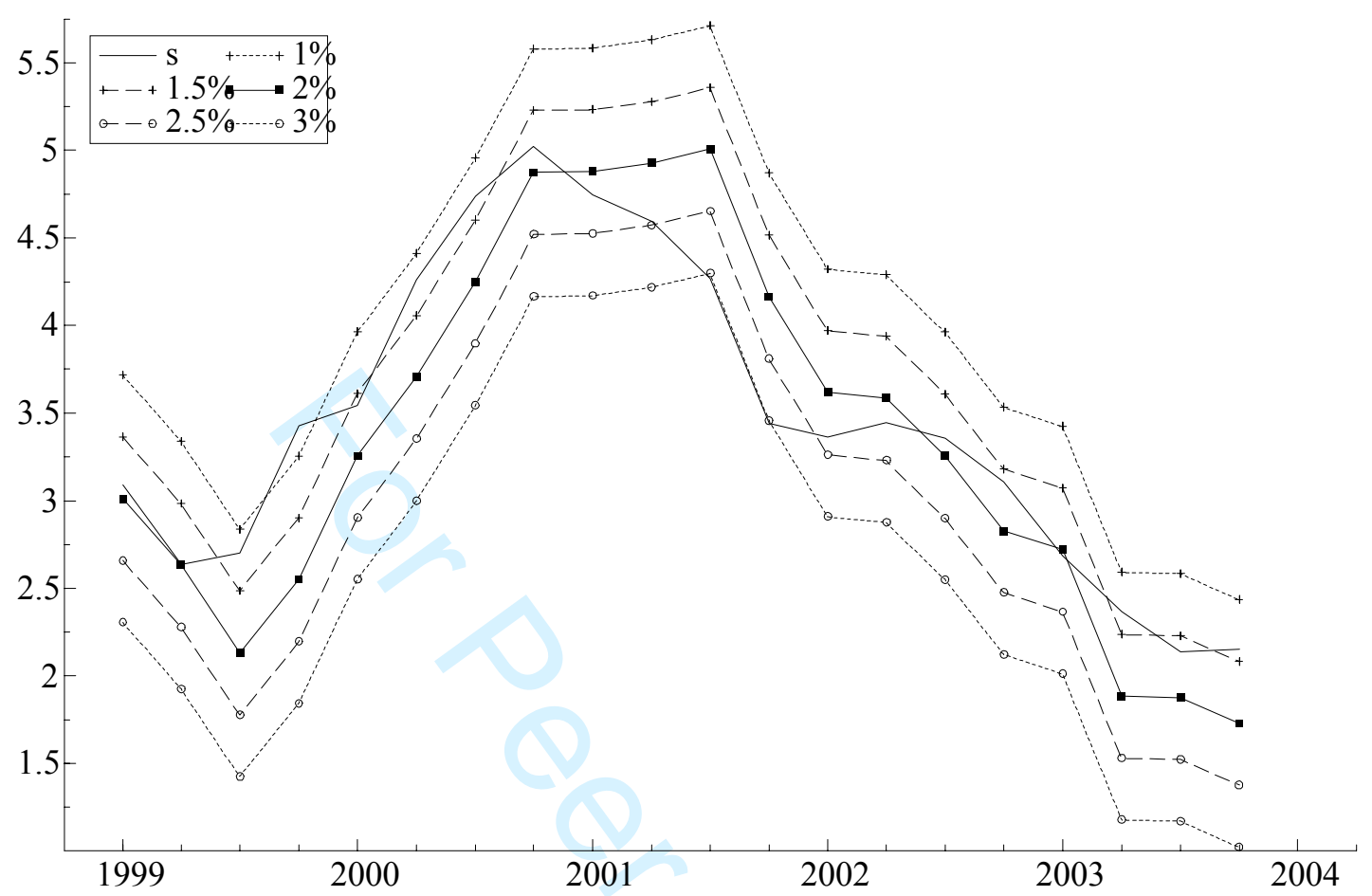

Figure 3: Actual and simulated short term nominal interest rates. 


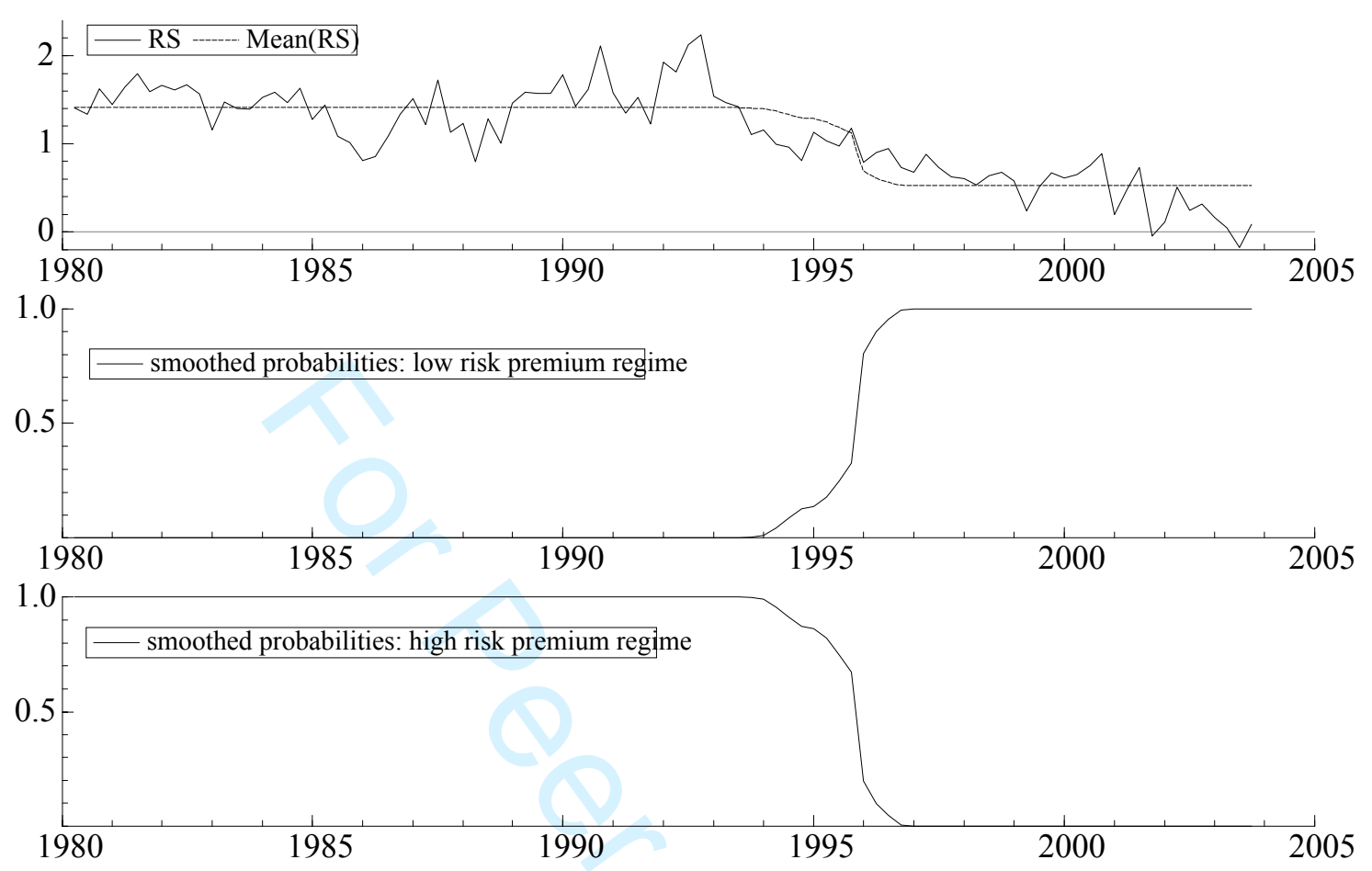

Figure 4: Real short term interest rate (RS), high and low risk premium regimes: mean component and smoothed probabilities. 